\title{
The influence of airtightness on contaminant spread in MURBs in cold climates
}

\author{
Philip Mckeen ( $₫)$, Zaiyi Liao \\ Department of Architectural Science, Ryerson University, Toronto, M5B 2K3, Canada
}

\begin{abstract}
Tall buildings in cold climates have unique challenges in maintaining indoor air quality due to stack effect. During the heating season, interior air buoyancy creates large pressure differentials in vertical shafts that can drive airflow from lower floors into upper floors. This pressure differential can result in the spread of contaminants throughout a building. Most recently, concern over COVID-19 has increased attention to the potential spread of airborne diseases in densely populated buildings. For many multi-unit residential buildings, suite ventilation has traditionally relied upon fresh air supplied through a mechanically pressurized corridor. In cold climates, large pressure differentials created by stack-effect can reduce the effectiveness of this approach. Multizone and CFD simulations are employed to analyze airflow and contaminant spread due to stack effect. Simulations are conducted on an idealized model of a 10-storey building using a range of experimentally derived airtightness parameters. Simulations demonstrate stack effect can reduce corridor ventilation to suites and even reverse the airflow for leakier buildings. Reduced airflow to suites can result in the accumulation of contaminants. Reversal of the airflow can allow contaminants from a suite to spread throughout the building. Contaminant spread is illustrated as a function of mechanical ventilation, building airtightness, and ambient temperatures. Strategies to reduce the influence of stack effect on mechanically pressurized corridors are discussed.
\end{abstract}

\author{
Keywords \\ MURBs ventilation; \\ contamination spread; \\ stack effect

\section{Article History} \\ Received: 12 October 2020 \\ Revised: 27 January 2021 \\ Accepted: 18 February 2021 \\ (c) Tsinghua University Press and \\ Springer-Verlag GmbH Germany, \\ part of Springer Nature 2021
}

\section{Introduction}

For many multi-unit residential buildings (MURBs), a pressurized corridor is used to supply fresh air and prevent the spread of contaminants. The supplied air is intended to provide ventilation to suites through door undercuts and prevent contaminants from entering the corridor. Maintaining a sufficient pressure differential between the corridor and suites may be a challenge for leakier buildings, particularly during cold ambient temperatures. The influence of stack effect may reduce the pressure differential and result in the reduction and reversal of airflow. The pressurized corridor approach has been critiqued as inadequate for providing ventilation and controlling contaminants effectively (CMHC 2003; Ricketts 2014). While MURBs developed today have moved away from using the pressurized corridor to provide ventilation, much of the existing building stock relies on this method. A survey (Leslie Jones \& Associates 1991) of 260 MURBs determined that 95\% utilized a corridor ventilation system.

This study investigates airflow dynamics and the spread of contaminants in MURBs with pressurized corridors. A range of parameters derived from experimental testing of MURBs are evaluated using multizone models and computational fluid dynamics (CFD). Parametric analysis is used to determine the sensitivity to which airtightness and mechanical ventilation affect airflow and contaminant spread. This paper aims to demonstrate how MURBs may be susceptible to contamination spread and recommends remedial measures to improve performance.

\subsection{Literature review}

Indoor air quality (IAQ) has evolved over the last century and has garnered increased attention toward health and comfort standards in buildings (ASHRAE 2009). This is

E-mail: pmckeen@ryerson.ca 
evident in the inclusion of IAQ criteria in sustainable rating systems and the World Health Organization's (WHO) declaration that healthy indoor air is a human right (Mølhave and Krzyzanowski 2003). As it is estimated that people spend approximately $65 \%$ of the time in their homes, the importance of IAQ in MURBs is paramount (Brasche and Bischof 2005). Many contaminants are often present in MURBs, and insufficient ventilation can result in their accumulation. The spread of airborne diseases and the recent outbreak of the COVID-19 virus has prompted increased discussion around airflow in buildings (Francisco et al. 2020).

\subsubsection{Nature of contaminants}

MURBs are subject to a range of airborne contaminants that may exist due to building construction and materials, occupants, or occupant activities (Francisco et al. 2020). Guidance from several organizations have indicated what constitutes acceptable concentrations of contaminants and recommended ventilation levels (Limb 1998). Recently, the spread of airborne diseases such as SARS (SARSCoV-1) and COVID-19 (SARS-CoV-2) has gained much attention.

The airborne spread of disease from an infected individual to a susceptible person occurs through particles known as aerosols. The particle movement is influenced by momentum, gravity, drag, and convection currents (Li et al. 2005; Tellier et al. 2019; Francisco et al. 2020). While gravity limits large droplets' travel distance, the microorganisms on aerosols, which measure under $10 \mu \mathrm{m}$, may stay airborne for prolonged periods (Figure 1). Early studies on SARS-CoV-2 suggest airborne viability to be upwards of 3-hours, similar to its measurement for SARS-CoV-1 (van Doremalen et al. 2020). Thus, undesirable airflow within MURBs due to stack effect, wind, or recirculating HVAC may permit disease transmission (Francisco et al. 2020).

Studies of disease outbreaks in hospitals and residential buildings have demonstrated that airflow throughout a building can facilitate infectious disease spread (Li et al. 2007).

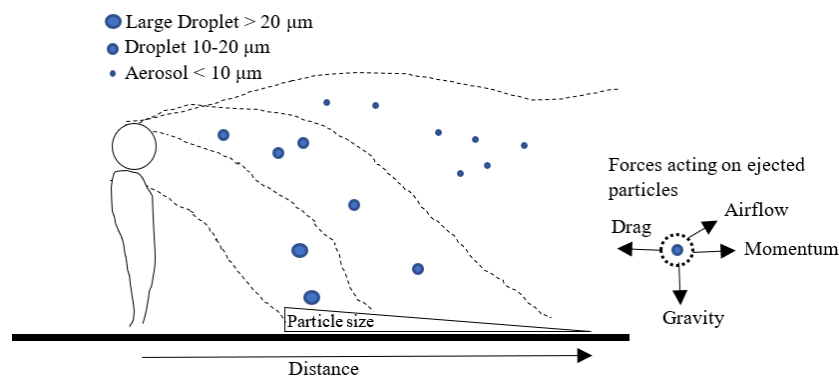

Fig. 1 Airborne transmission of droplets and aerosols, and the forces that act on them
Several studies have linked infection locations with the airflow patterns observed using tracer gas. The aerosol travel distance appeared to be related to building design ( $\mathrm{Li}$ et al. 2007). While aerosols concentrations in a building may be reduced through ventilation, little data exist on the appropriate dilution required to abate such hazard.

During a pandemic, the potential for airborne spread in MURBs could be a significant problem. The quarantine of infected individuals within MURBs may facilitate transmission if the airflow is uncontrolled within the building. Airborne transmission may be considered an opportunistic route (Tellier et al. 2019), and the extent of its viability may depend on the environmental conditions and exposure duration of occupants. Areas with virus-laden aerosol, due to many infected individuals and poor ventilation, may support transmission. In MURBs, the exposure duration may be high if the spread of contaminated air is not contained.

Stack effect during cold ambient temperatures can affect a buildings' pressure regime and reduce ventilation of suites on lower floors. Studies have found increased $\mathrm{CO}_{2}$ concentration in suites on lower floors due to stack effect during the winter months (Ricketts 2014). Low $\mathrm{CO}_{2}$ concentrations in occupied suites are indicative that other common pollutants, such as bio-effluents, are being diluted sufficiently.

Methods of maintaining IAQ include limiting contaminant sources, supplying fresh air to dilute contaminants, and containing contaminants through pressurization (Persily 2015; ASHRAE 2017). Minimum requirements for ventilation are prescribed in ASHRAE 62.1, and recently, ASHRAE 62.2-2019 has specifically addressed all residential dwellings (ASHRAE 1999). However, these standards do not specify criteria for preventing airborne disease transmission. Several strategies for MURBs, including ventilation dilution and pressurization, are detailed in the 2014 ASHRAE Position Document on Airborne Infectious Diseases (Francisco et al. 2020) and IAQ Guide (ASHRAE 2009).

\subsubsection{Ventilation performance}

Make-up air unit (MAU) supplying air to corridors often fails to provide adequate pressurization or ventilation to suites. Common complaints from occupants included the transfer of odours and tobacco smoke from suites to the corridor. As ventilation delivered to suites can vary throughout the building, the perception of IAQ by occupants may be mixed and go unabated throughout the building's lifespan. Several studies have identified conditions where corridors area at negative pressures relative to suites. These studies highlight the inadequate performance of corridor 
pressurization as a means of providing suite ventilation and preventing contaminant spread.

Studies involving tracer gas have found a considerable variation in ventilation delivered to suites. For instance, a study of ten MURBs (Edwards 1999) found corridor supplied ventilation to suites ranged between 10 and $70 \mathrm{~L} / \mathrm{s}$. Corridor ventilation can also vary significantly per floor, as determined by a study (Ricketts 2014), where supply ranged from $10 \mathrm{~L} / \mathrm{s}$ to $33 \mathrm{~L} / \mathrm{s}$ per suite on different floors.

Stack effect has been observed to drive airflow from suite to corridor, permitting contaminated air to enter vertical shafts (CMHC 2005; Wray et al. 1998; Ricketts 2014; Strege and Ferreira 2017). A study by the NRC evaluated tracer gas spread in a 5-storey MURB with an outdoor temperature of $11{ }^{\circ} \mathrm{C}$ (Shaw 1993). Tracer gas released on the ground floor migrated into stairwells and elevator shafts. The rise of tracer gas through shafts and into corridors suggests that mechanical pressurization was inadequate to overcome stack effect. Suites on the $2^{\text {nd }}$ floor measured between 2.5 and 3.9 parts per billion (ppb), and suite on the $5^{\text {th }}$ floor between 2.5 and $7.8 \mathrm{ppb}$. The variation suggested that supply air distribution to suites of a floor is not equal, and some suites may be over-ventilated or under-ventilated. Higher concentrations measured on the leeward suites suggest wind influenced the distribution of tracer gas within a floor. The combination of wind and stack effect can increase the likelihood of contaminant spread.

A study of a 13-story apartment (De Paepe et al. 2019) utilizing pressurized corridors measured pressure differentials between the stairwell and corridor during ambient temperatures of $7{ }^{\circ} \mathrm{C}$. The stairwell pressure relative to the corridor was approximately $-4 \mathrm{~Pa}$ on the first floor and $+8 \mathrm{~Pa}$ on the top floor. This implies airflow in and out of vertical shafts can be expected.

A study of several tall hotel buildings (Strege and Ferreira 2017) measured the pressure differential between the corridor and vertical shafts during winter conditions. On lower floors, stairwell pressures were negative relative to the corridor, with an average differential of $-11.0 \mathrm{~Pa}$. On the upper floors, stairwell pressures measured mostly positive, with an average differential of $10.2 \mathrm{~Pa}$. In two buildings, the upper corridors were measured slightly positively relative to the shafts, perhaps demonstrating that corridor pressurization can prevent infiltration.

A study (Ricketts et al. 2014) investigated the airflow through a 13-storey MURB using tracer gas. Under winter conditions, reduced pressurization of lower floors resulted in under-ventilated suites and increased airflow potential from suite to corridor. Tracer gas confirmed the spread of air through vertical shafts could enter suites on upper floors (ASHRAE 2009).
For the corridor pressurization system to work, air supplied to the corridor must be sufficient to maintain a positive pressure relative to suites. Since leakier buildings allow more infiltration under stack effect, more corridor supply ventilation is required to maintain compartmentalization (Persily 2004). It has been demonstrated that increasing the corridor's airtightness could result in an increased corridor pressure relative to suites (CMHC 2005). However, since the suite doors are intended to deliver ventilation to the suite, reducing the leakage area may reduce ventilation.

\section{Airflow in MURBs}

The spread of contaminants is dependent on the airflow dynamics of a building. Airflow will occur where pressure differentials and leakage exist. Environmental forces, such as stack effect and wind, can create considerable pressure differentials that cause airflow between suites, corridors, and vertical shafts. Mechanical pressurization can counteract such environmental forces and prevent infiltration. Depending on the building's airtightness and corridor ventilation, the MURB's airflow dynamics may prevent or facilitate the spread of contaminants.

\subsection{Stack effect}

Stack effect is often the dominant environmental force driving air movement in buildings of cold climates during winter periods (Ricketts 2014; Ricketts et al. 2014). The stack pressure is a function of the building height and indoor/outdoor temperature. Increasing the building height and temperature difference can lead to a significant stack pressure (Eq. (1)).

$\Delta P=\frac{g P}{R}\left(\frac{1}{T_{\mathrm{o}}}-\frac{1}{T_{\mathrm{i}}}\right) h$

where, $h=$ building height $(\mathrm{m}) ; g=$ gravitational acceleration $\left(\mathrm{m} / \mathrm{s}^{2}\right) ; P=$ absolute atmospheric pressure $(\mathrm{Pa}) ; R=$ gas constant of air $(8.314 \mathrm{~J} /(\mathrm{mol} \cdot \mathrm{K})) ; T_{0}=$ absolute temperature of outside air $(\mathrm{K}) ; T_{\mathrm{i}}=$ absolute temperature of inside air $(\mathrm{K})$.

The neutral pressure plane (NPP) location occurs where the hydrostatic pressure in the shaft equals the outdoor pressure. When leakage is equally distributed along the vertical axis, the NPP will occur at mid-height. In colder seasons, air below the NPP will enter vertical shafts and begin to rise. As air rises in shafts above the NPP, it will begin flowing out of the shaft and into floors and suites. Contaminants originating from the ground floor may travel to the floors above the NPP. The supply of air to corridors can pressurize the building and move the NPP location 
beneath the lowest floor. When this occurs, infiltration into the corridor is prevented.

\subsection{Airflow through leakage area}

The airflow through an orifice can be estimated using analytical equations, such as the flow equation appropriate for sharp-edged orifices (Eq. (2)). The orifice can be defined with a cross-sectional area perpendicular to the airflow, known as the effective flow area, $A_{\mathrm{e}}$. A flow coefficient, $C_{\mathrm{d}}$, is used to account for friction and dynamic losses from laminar and turbulent flow. The flow can be approximated based on the leak geometry. It is common for narrow openings common in walls and floors to use a $C_{\mathrm{d}}$ range between 0.6 and 0.7. Large openings can expect turbulence and the presence of stationary vortices, and $C_{\mathrm{d}}$ of 0.35 to 0.5 is suggested (Klote and Milke 2002). When tailored with the proper coefficients, the orifice equation has shown good agreement with experiments and is deemed acceptable for the study of air movement and smoke spread through leakage paths in buildings (Klote and Milke 2002).

$Q=C_{\mathrm{d}} A_{\mathrm{e}} \sqrt{\frac{2 \Delta p}{\rho}}$

where, $Q=$ volumetric flow rate $\left(\mathrm{m}^{3} / \mathrm{s}\right) ; C_{\mathrm{d}}=$ discharge coefficient; $A_{\mathrm{e}}=$ effective flow area $\left(\mathrm{m}^{2}\right) ; \rho=$ density of gas $\left(\mathrm{kg} / \mathrm{m}^{3}\right) ; \Delta p=$ pressure differential $(\mathrm{Pa})$.

Airflow into a suite is a function of pressure differentials and the effective areas of the leakage found in the envelope, suite/corridor, and shaft/corridor compartments. Figure 2 illustrates the primary airflow paths that exist within a MURB floor. Note that the direction of these flows may change depending on the pressure differential. Figure 3 shows an

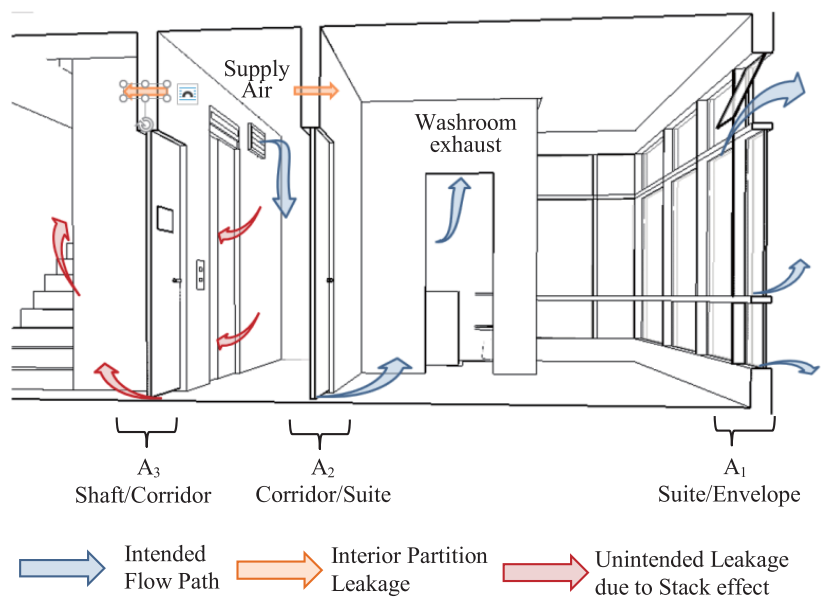

Fig. 2 Typical airflow patterns within a MURB floor with corridor supplied air, note direction of flow may change depending on pressure differentials

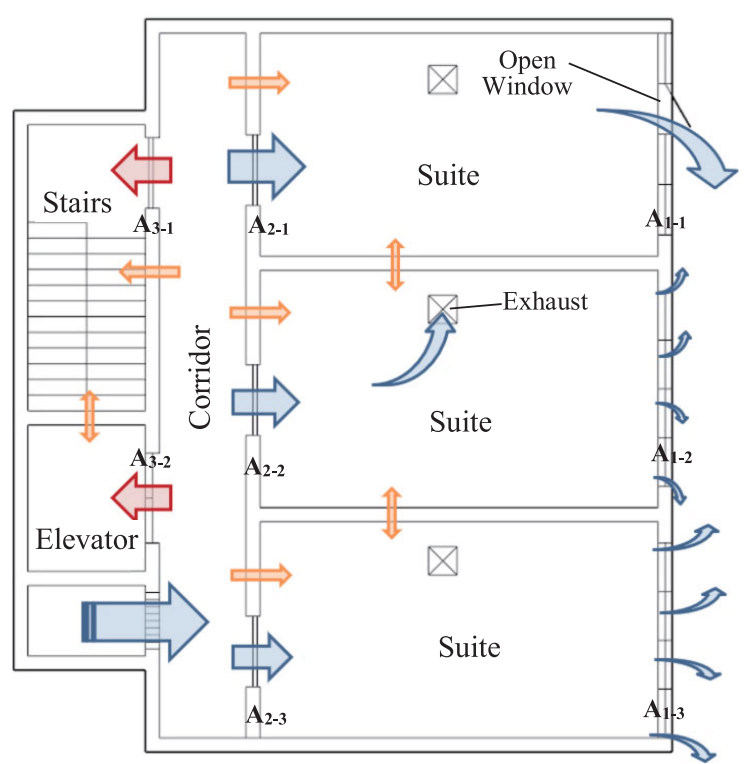

Fig. 3 Idealized floorplan of a MURB identifying primary leakage paths and shafts, MAU supply, and exhaust fans

idealized MURB floorplan containing three suites, a corridor, and vertical shafts.

\subsubsection{Leakage area of compartments}

Airflow through a MURB is affected by the leakage area of the suite, corridor, and shaft compartments. The leakage area of several primary leakage paths are explored using several experiments on MURBs which determined the airtightness of walls and doors. The primary paths of interior compartments are often located at doors. While walls are often tight relative to doors, their vast surface area can cumulate significant leakage area.

\section{Closed doors}

Investigation of one particular MURB determined that suite doors' undercut depth ranged from $0 \mathrm{~mm}$ to $22 \mathrm{~mm}$, with an average of $6 \mathrm{~mm}$ (Ricketts 2014). The variations may exist due to numerous factors that include workmanship, manufacturer tolerances, and door modifications such as weather-stripping. The pressurization testing of several suite doors from a single MURB revealed range in airflow of 30 to $210 \mathrm{~L} / \mathrm{s}$ at $75 \mathrm{~Pa}$. These experimental measurements recorded by flow coefficient, $C$, and flow exponent, $n$, are depicted in Figure 4.

In a separate study, several doors' leakage area was physically measured and subject to a $25 \mathrm{~Pa}$ pressure differential (Gross and Haberman 1989). The correlation of leakage area and airflow is notable, with increased leakage area resulting in increased flow, as seen in Figure 4. However, leakage geometry of door gaps, particularly when increasingly narrow, may change the flow dynamics. A mix 


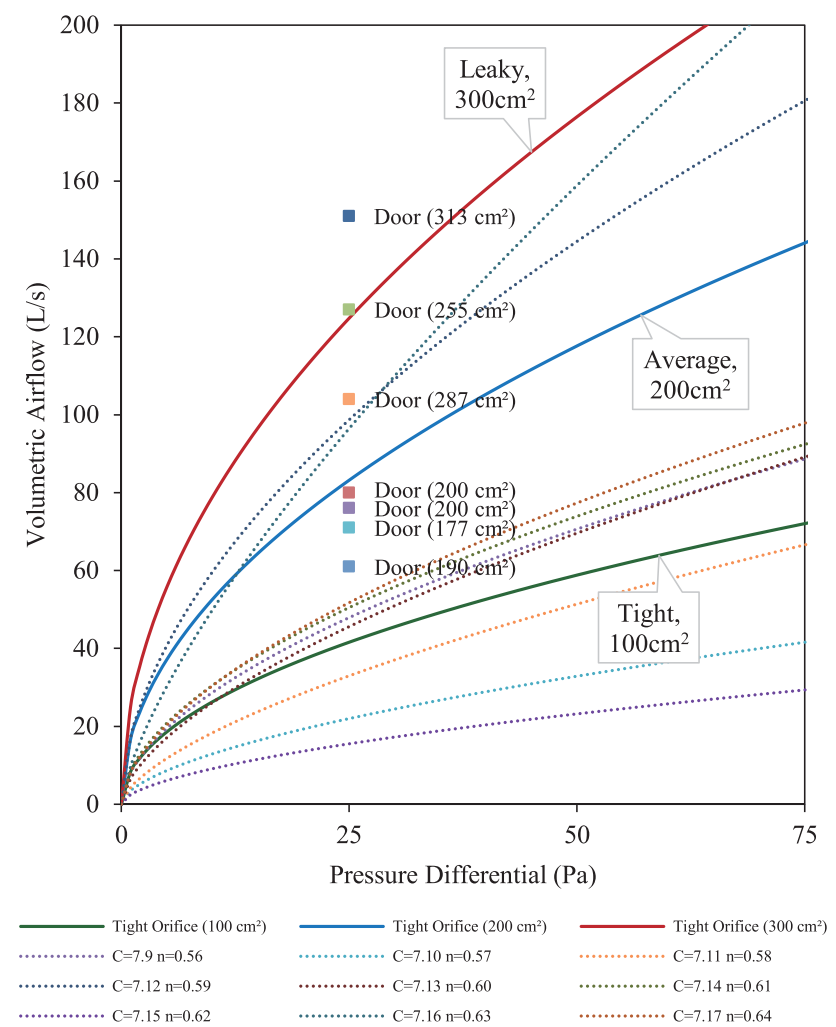

Fig. 4 Airtightness of closed doors from experimental studies and the orifice approximation defined as "tight", "average" and "leaky"

of laminar and turbulent is most accurately described by Gross and Haberman's modified flow equations (Gross and Haberman 1989; Gross 1991). Despite this, the orifice equation provides a relatively good representation of door leakage for the doors tested, as illustrated by the tight, average, and leaky doors emphasized in Figure 4.

\section{Exterior envelope}

Airtightness testing of MURBs envelopes demonstrated a wide variance between buildings. Variation within the same building is also expected and can often be attributed to workmanship and construction details (Tamura and Shaw 1976). Early studies on building airtightness by Tamura and Shaw (1976) arbitrarily defined the envelope as tight, average, and leaky to measure approximately $0.5,1.5$, and $3.0 \mathrm{~L} / \mathrm{s} / \mathrm{m}^{2}$ at $75 \mathrm{~Pa}$, respectively. Figure 5 illustrates the airflow in tight, average, and leaky envelopes defined by Tamura and Shaw (1976) when using a flow exponent of 0.65 . For a comparison, airtightness measurements of a MURB undergoing an envelope retrofit determined the pre-retrofit and post-retrofit airtightness to be $3.9 \mathrm{~L} / \mathrm{s} / \mathrm{m}^{2}$ and $1.9 \mathrm{~L} / \mathrm{s} / \mathrm{m}^{2}$ at $75 \mathrm{~Pa}$, respectively (Ricketts 2014).

\section{Vertical shafts}

The stairwell and vertical shafts' leakage area will depend

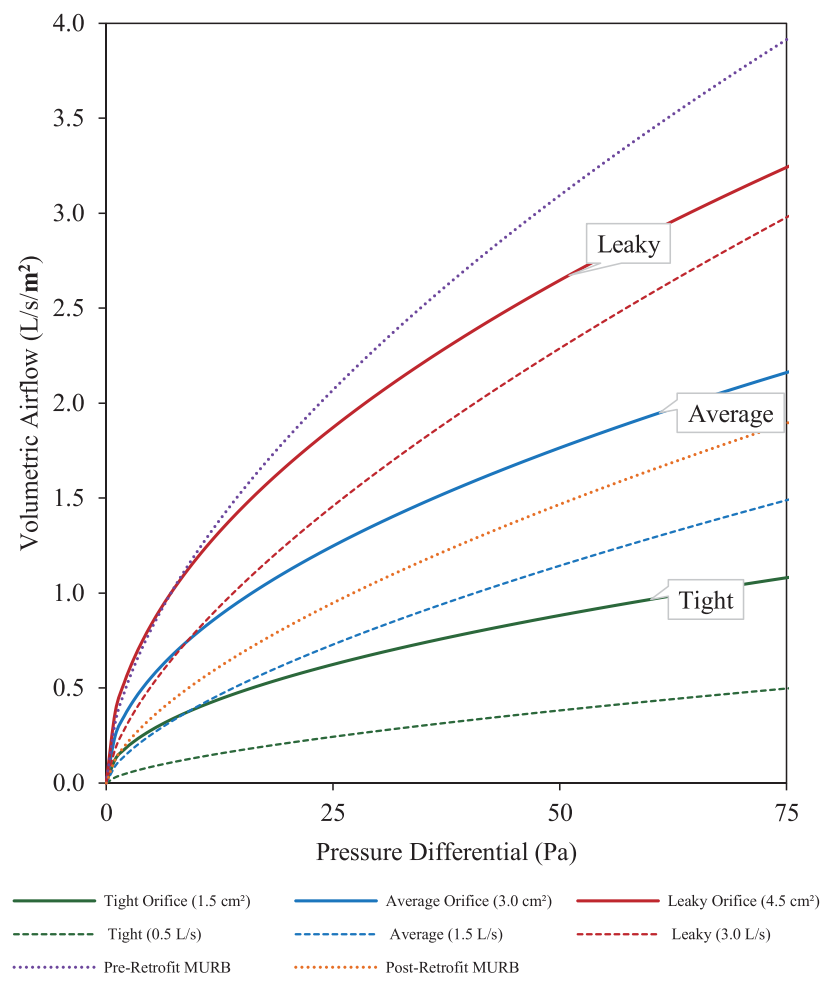

Fig. 5 Airtightness of building envelopes as determined by several blower door test and an orifice approximation defined as "tight", "average" and "leaky"

on the airtightness properties of the enclosure and doors. Other openings, such as hoistway vents, are often found at the top of elevator shafts (Klote and Milke 2002). Such vents can be a significant source of exfiltration and raise the NPP within the building. Regulations have allowed for this area to be reduced by several means, including the use of automatic dampers (Kleinberg and Neri 2017).

\subsubsection{Quantifying leakage of compartments}

The terms "tight", "average", and "leaky" are ambiguous as they are defined differently in industry and standards. In this study, the terms are used to describe the range of airtightness measurements in Figure 4 and Figure 5, which capture a range of typical MURBs. The values selected are noted in Table 1.

Airflow through multiple leakage paths can be analyzed using the effective flow area concept. The effective flow area is defined as the cross-sectional area capable of producing equal airflow.

The airflow paths can be in parallel with one another, in series, or both. The effective flow area of parallel paths is the summation of the individual leakage areas, determined by Eq. (3).

$A_{\mathrm{e}}=\sum_{i=1}^{n} A_{i}$

where, $A_{\mathrm{e}}=$ effective flow area $\left(\mathrm{m}^{2}\right) ; A_{i}=$ leakage area $i\left(\mathrm{~m}^{2}\right)$. 
Table 1 Idealized flow paths and leakage area

\begin{tabular}{cccc}
\hline $\begin{array}{c}\text { Flow } \\
\text { path ID }\end{array}$ & $\begin{array}{c}\text { Flow path } \\
\text { description }\end{array}$ & $\begin{array}{c}\text { Normalized leakage } \\
\text { area }\left(\mathrm{cm}^{2} / \mathrm{m}^{2}\right)\end{array}$ & $\begin{array}{c}\text { Leakage area } \\
\left(\mathrm{cm}^{2}\right)\end{array}$ \\
\hline$A_{1}$ & Exterior walls (tight) & 1.5 & 100 per suite \\
$A_{1}$ & Exterior walls (average) & 3.0 & 200 per suite \\
$A_{1}$ & Exterior walls (leaky) & 4.5 & 300 per suite \\
$A_{1}$ & Exterior walls (open & $\mathrm{n} / \mathrm{a}$ & 1000 per suite \\
& window) & $\mathrm{n} / \mathrm{a}$ & 100 \\
$A_{2}$ & Suite doors (tight) & $\mathrm{n} / \mathrm{a}$ & 200 \\
$A_{2}$ & Suite doors (average) & $\mathrm{n} / \mathrm{a}$ & 300 \\
$A_{2}$ & Suite doors (leaky) & $\mathrm{n} / \mathrm{a}$ & 200 \\
\hline$A_{3-1}$ & Stairwell door & $\mathrm{n} / \mathrm{a}$ & 700 \\
$A_{3-2}$ & Elevator shaft doors & &
\end{tabular}

*Assuming exterior wall surface area of $66.6 \mathrm{~m}^{2}$ per suite.

${ }^{*}$ Assuming a small opening of a window, $100 \mathrm{~cm} \times 10 \mathrm{~cm}$.

The effective flow area for a series of leakage areas can be determined by Eq. (4). The effective area is influenced by the most restrictive path in a series of leaks. Similarly, a large opening in a series of small openings will be insignificant on the net airflow. The effective area of a compartment such as a suite, airflow will depend on the effective leakage area of the envelope $A_{1}$ and corridor $A_{2}$.

$A_{\mathrm{e}}=\left(\sum_{i=1}^{n} \frac{1}{A_{i}^{2}}\right)^{-\frac{1}{2}}=\left(\frac{1}{A_{1}^{2}}+\frac{1}{A_{2}^{2}}\right)^{-\frac{1}{2}}$

This concept can illustrate the influence of leakage area on airflow for an assumed pressure differential. The effective area of a suite changes significantly with variation in the airtightness of the envelope and corridor. This is illustrated in Figure 6 using the range of leakage areas established in Table 1. Tighter envelopes can reduce the range of effective leakage area. However, the presence of an open window can nullify any increase in airtightness. Relying solely on the envelope for airtightness can result in significant changes to the effective area due to occupant behavior. Increasing the corridor's airtightness may prove to be more reliable approach.
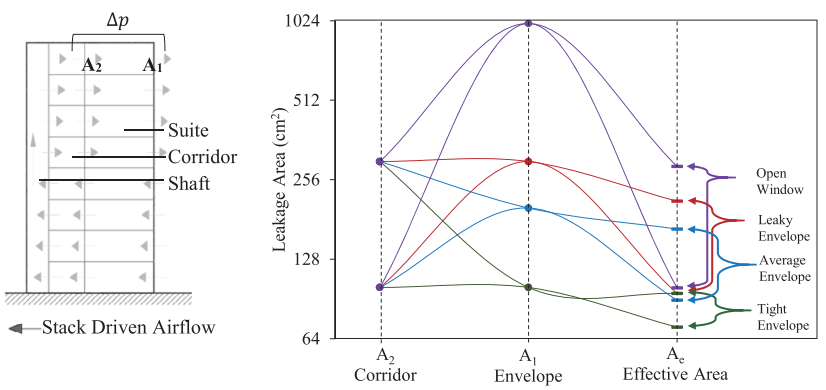

Fig. 6 Variation in the leakage area of the corridor $A_{2}$, and envelope $A_{1}$, can result in a wide range of effective area

\section{Methodology}

Experimental testing demonstrated a wide range of airtightness exists amongst MURBs. The influence of airtightness on a MURB with pressurized corridors can be evaluated using numerical simulations. An idealized model of a 10-storey MURB was developed using the floor plan illustrated in Figure 3. A parametric analysis evaluated the change in airtightness, and mechanical ventilation has on airflow and contaminant spread. The leakage parameters capturing the range of airtightness values of typical MURBs are described in Table 2 . Leakage areas represent the primary path of leakage at the building envelope, $A_{1}$, the corridor, $A_{2}$, and vertical shafts, $A_{3}$.

Simulations of the idealized model were conducted with an ambient temperature of $0{ }^{\circ} \mathrm{C}$ and an indoor temperature of $20{ }^{\circ} \mathrm{C}$. The parametric study evaluated the effect of airtightness and MAU on the building airflow and pressure profile. Simulations used a combination of leaky and tight values for envelope and corridors (Sim-X1, Sim-X2, Sim-X3, Sim-X4). The influence of increasing the tightness of the vertical shaft was explored in Sim-X5. The effect of reducing MAU supply air to the $9^{\text {th }}$ floor was explored in Sim-X6. The influence of variations in ventilation and airtightness on airflow and pressure profiles were explored for select building parameters described in Table 2. This included simulations conducted with suite exhaust fans.

Select simulations of the idealized model parameters described in Table 2 were used to determine the effect of airtightness and MAU supply on contaminant spread. The spread of airborne disease was modeled by accounting for the exhalation of three infected individuals with a breathing rate of $300 \mathrm{~L} / \mathrm{h}$ each, representing a person in a reclined position (Jiang et al. 2009). The contaminant source was specified in the first-floor suites, as the lowest floor is most prone to infiltration due to stack effect. The exhaled air was treated as a trace gas and concentration was predicted throughout the building and visualized in CFD simulation.

Table 2 Leakage area for envelope and corridor per floor used in CONTAM and FDS

\begin{tabular}{lcccc}
\hline Sim-ID & Envelope, $A_{1}$ & Corridor, $A_{2}$ & Shaft, $A_{3}$ & $\begin{array}{c}\text { MAU } \\
(\mathrm{L} / \mathrm{s} / \text { floor })\end{array}$ \\
\hline Sim-X1 & $900 \mathrm{~cm}^{2}$ (leaky) & $900 \mathrm{~cm}^{2}$ (leaky) & $1100 \mathrm{~cm}^{2}$ & 120 \\
Sim-X2 & $300 \mathrm{~cm}^{2}$ (tight) & $300 \mathrm{~cm}^{2}$ (tight) & $1100 \mathrm{~cm}^{2}$ & 120 \\
Sim-X3 & $900 \mathrm{~cm}^{2}$ (leaky) & $300 \mathrm{~cm}^{2}$ (tight) & $1100 \mathrm{~cm}^{2}$ & 120 \\
Sim-X4 & $300 \mathrm{~cm}^{2}$ (tight) & $900 \mathrm{~cm}^{2}$ (leaky) & $1100 \mathrm{~cm}^{2}$ & 120 \\
\hline Sim-X5 & $900 \mathrm{~cm}^{2}$ (leaky) & $900 \mathrm{~cm}^{2}$ (leaky) & $700 \mathrm{~cm}^{2}$ & 120 \\
\hline Sim-X6 & $900 \mathrm{~cm}^{2}$ (leaky) & $900 \mathrm{~cm}^{2}$ (leaky) & $1100 \mathrm{~cm}^{2}$ & $120^{*}$ \\
\hline
\end{tabular}

$* 9^{\text {th }}$ floor MAU supply air reduced to $20 \mathrm{~L} / \mathrm{s}$. 


\subsection{Numerical simulation}

CONTAM, a multizone model, and Fire Dynamics Simulator (FDS), a multi-physics CFD model, were used to predict the airflow and contaminant spread. Multizone models are computationally fast and can produce accurate results for large buildings. Multizone models assume the uniformity of pressure, temperature and contaminant concentration amongst zones. CFD models can solve fluid flow through physically modeled openings. The airflow calculation through openings is integral to determining the building airflow dynamics induced by stack effect, and CFD provides an alternative approach to the multizone model.

The building modeled in CONTAM (Version 3.2) considers each compartment an interconnected zone where the air is well mixed (Dols and Polidoro 2015). Mass balance equations are used to solve for static pressure and determine the airflow between each zone. The airflow between zones $i$ and $j, F_{i, j}(\mathrm{~kg} / \mathrm{s})$, is calculated by a function of pressure differential along the leakage path (Eq. (5)). In this study, the airflow was calculated using the orifice equation previously identified (Eq. (2)).

$F_{i, j}=f\left(P_{i}-P_{j}\right)$

The mass of air, $m_{i}(\mathrm{~kg})$, in zone $i$ is given by the ideal gas law, where $V$ is the volume $\left(\mathrm{m}^{3}\right), \rho$ is the air density $\left(\mathrm{kg} / \mathrm{m}^{3}\right)$, $P$ is the air pressure $(\mathrm{Pa})$, and $T$ is the temperature $(\mathrm{K})$ :

$m_{i}=\rho_{i} V_{i}=\frac{P_{i} V_{i}}{R T_{i}}$

In transient solutions, the principle of conservation of mass is given in Eq. (7), where $Q_{j, i}$ is the airflow $(\mathrm{kg} / \mathrm{s})$ between zones $j$ and $i$, and $t$ is the time.

$\frac{\partial m_{i}}{\partial t}=\rho_{i} \frac{\partial V_{i}}{\partial t}+V_{i} \frac{\partial \rho_{i}}{\partial t}=\sum_{j} Q_{j i}+Q_{i}$

FDS (Version 6.6.1) is a CFD software that is commonly applied in the study of fire and smoke spread. FDS numerically solves Navier-Stokes equations appropriate for low speed, thermal buoyancy driven flow. Turbulence is calculated using the Smagorinsky form of large eddy simulation (LES). Partial differential governing equations (Eqs. (8)-(10)) for continuity, species concentration, momentum are solved sequentially to predict the transport of air and contaminants. Further description of the model is provided in the FDS Technical Reference Guide (McGrattan et al. 2019).

$$
\frac{\partial}{\partial t}+\nabla \cdot \rho u=0
$$

$\frac{\partial \rho Y_{\propto}}{\partial t}+\nabla \cdot\left(\rho Y_{\propto} u\right)=\nabla \cdot\left(\rho D_{\propto} \nabla Y_{\propto}\right)+\dot{m}_{\propto}^{\prime \prime \prime}$

$\frac{\partial \rho u}{\partial t}+\nabla \cdot(\rho u u)=-\nabla \tilde{p}-\nabla \cdot \tau+\left(\rho-\rho_{0}\right) g$

where $u$ is the velocity vector, $Y_{\propto}$ is the mass fraction of species $\propto, D_{\propto}$ is the turbulent diffusion coefficient of species $\propto, h_{\mathrm{s}}$ is the mass-weighted average enthalpy of the lumped species, $\dot{m}_{\propto}^{\prime \prime \prime}$ is the mass-production rate per unit volume of species $\propto, \tilde{p}$ is the pressure perturbation, and $\tau$ is the viscous stress tensor.

In FDS, the idealized MURB was physically modeled with openings defined by the parameters in Table 2. The computational domain volume was $32 \mathrm{~m}$ high by $9 \mathrm{~m}$ by $6 \mathrm{~m}$, which extended beyond the volume of the structure. Open boundary conditions were utilized in front of the façade and above as illustrated in Figure 7. A mesh resolution of $10 \mathrm{~cm}$ cells was used for simulations.

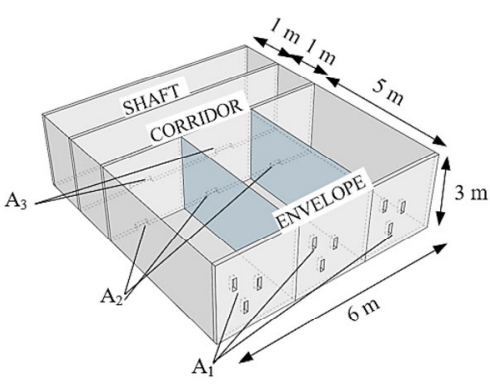

(a)

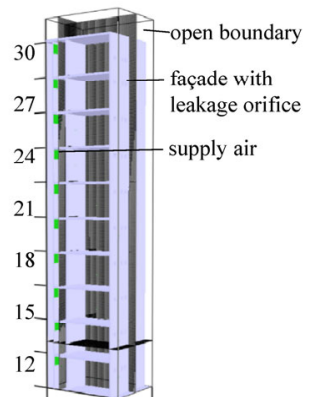

(b)
Fig. 7 Idealized 10-storey MURB showing prominent leakage paths in a floor schematic (a) and section (b) used in the CFD simulation

\subsection{Limitations}

Simulations utilized an idealized model that captures the primary leakage paths of a typical MURB. A challenge in simulating airflow is accounting for the wide variation of airtightness in MURBs. To address this, leakage parameters were derived from a range of airtightness testing of several doors and building envelopes. The models neglect some paths of leakage, such as between suites and floors, for example. These are generally small in comparison to primary airflow paths identified, and studies have shown that zero floor leakage is generally appropriate for evaluating pressure differentials with buildings due to stack effect (Klote and Milke 2002). Leakage area of the vertical shaft top vent was specified to be $930 \mathrm{~cm}^{2}$ in all simulations. Increasing the opening size will allow for more air to escape through the top vent, which will raise the NPP and increase the airflow entering from corridors.

The simulations predict airflow driven by mechanical ventilation and stack effect only. Other environmental 
conditions such as wind were not included in simulations to reduce the complexity of results. While it is understood that wind can affect the pressure and airflow within a building, the justification for considering only stack effect can be made. While wind gust are confined to short durations, stack effect occurs consistently when ambient temperature differentials occur. Additionally, stack pressures become increasingly dominant as for taller building and colder climates (Finch et al. 2009; Shaw and Tamura 1977; Ricketts 2014).

\section{Results}

Numerical simulations predicted the pressure, airflow, and contaminant concentrations within the MURB shaft, corridors, and suites. CONTAM was utilized for all simulated cases, and FDS was utilized for select simulations. Due to clarity in steady-state predictions, results from CONTAM are used to express the findings of airflow and pressure distribution. Contaminant spread is illustrated graphicly in FDS simulations. A comparison of the results of both approaches is included for several examples. In general, close agreement was obtained in airflow and pressure predictions.

\subsection{Airflow dynamics}

Numerical simulations predicted the pressure and airflow within shaft, corridor and suites at each level. Simulations in CONTAM and FDS provided similar airflow predictions as described in Table 3, which shows the results of Sim-X1, a MURB with leaky corridors and envelope. Infiltration is predicted on the lowest floors, which results in the spread of suite contaminates into the vertical shaft. Upper floors suites receive considerably more airflow, which is a result of stack driven flow.
Transient simulations in FDS provided relatively close agreement with CONTAM. Figure 8 shows the predictions of airflow and pressure differential between the building and exterior at the $1^{\text {st }}$ floor. The FDS simulations provided similar results for grid cell sizes of 5 and $10 \mathrm{~cm}$.

\subsubsection{Steady-state predictions}

Simulations demonstrated that airtightness can influence the airflow characteristics. The predicted airflow and pressure differentials for each floor. Simulation results are shown in Figures 9-14 and illustrate the airflow from MAU to suites (blue) and the airflow out of suites (green). The pressure relative to the exterior is shown for the vertical shaft, corridor, and suites.

With a leaky envelope and corridor in Sim-X1, airflow from suites on lower floors entered vertical shafts, noted by the negative airflow (a) in Figure 9. While upper floors receive increased ventilation from the MAU, a portion of this air may include air previously in suites on the lower floor (b). Thus, while ventilation provided to the suites may be increased, the air may contain contaminants.

Increased airtightness of the envelope and corridor reduced the airflow into vertical shafts and positively pressured corridors (Figure 10). As a result, the spread of contaminants is prevented. With a tight envelope and corridor, Sim-X2 provided suites with ventilation of between $54 \mathrm{~L} / \mathrm{s}$ and $100 \mathrm{~L} / \mathrm{s}$ per floor. In contrast, a leaky envelope and corridor in Sim-X1 resulted in suites with ventilation between -79 and $210 \mathrm{~L} / \mathrm{s}$ (Figure 9). Thus, some lower suites did not receive fresh air from the corridor, and the infiltration of air into the corridor occurred.

With a tight envelope and corridor, enough pressure is created to prevent air infiltration from suites into the corridor and vertical shafts. Insufficient airtightness results in negative pressure towards the bottom of the vertical

Table 3 Model predictions of pressure and airflow for Sim-X1

\begin{tabular}{|c|c|c|c|c|c|c|c|c|}
\hline \multirow[b]{3}{*}{ Floor } & \multicolumn{4}{|c|}{ CONTAM (Zone-Model) } & \multicolumn{4}{|c|}{ FDS (CFD-Model) } \\
\hline & \multicolumn{3}{|c|}{ Pressure $(\mathrm{Pa})$} & \multirow{2}{*}{$\frac{\text { Airflow (L/s) }}{\text { Into suites }}$} & \multicolumn{3}{|c|}{ Pressure $(\mathrm{Pa})$} & \multirow{2}{*}{$\frac{\text { Airflow }(\mathrm{L} / \mathrm{s})}{\text { Into suites }}$} \\
\hline & Shaft & Corridor & Suite & & Shaft & Corridor & Suite & \\
\hline 10 & 15.2 & 14.3 & 6.5 & 210 & 14.9 & 13.4 & 6.5 & 235 \\
\hline 9 & 12.6 & 12.0 & 5.4 & 194 & 12.4 & 11.2 & 4.9 & 218 \\
\hline 8 & 10.0 & 9.7 & 4.2 & 177 & 9.8 & 9.0 & 3.9 & 196 \\
\hline 7 & 7.5 & 7.3 & 3.0 & 156 & 7.2 & 6.7 & 2.7 & 172 \\
\hline 6 & 4.9 & 4.9 & 1.8 & 132 & 4.6 & 4.4 & 1.5 & 141 \\
\hline 5 & 2.3 & 2.3 & 0.5 & 101 & 2.1 & 2.2 & 0.5 & 103 \\
\hline 4 & -0.3 & 0.1 & -0.6 & 62 & -0.5 & 0.1 & -0.4 & 51 \\
\hline 3 & -2.9 & -1.3 & -1.3 & 3 & -2.9 & -1.1 & -1.1 & -29 \\
\hline 2 & -5.5 & -2.1 & -1.7 & -49 & -5.1 & -2.0 & -1.5 & -68 \\
\hline 1 & -8.1 & -3.4 & -2.3 & -79 & -7.7 & -3.1 & -2.0 & -93 \\
\hline
\end{tabular}




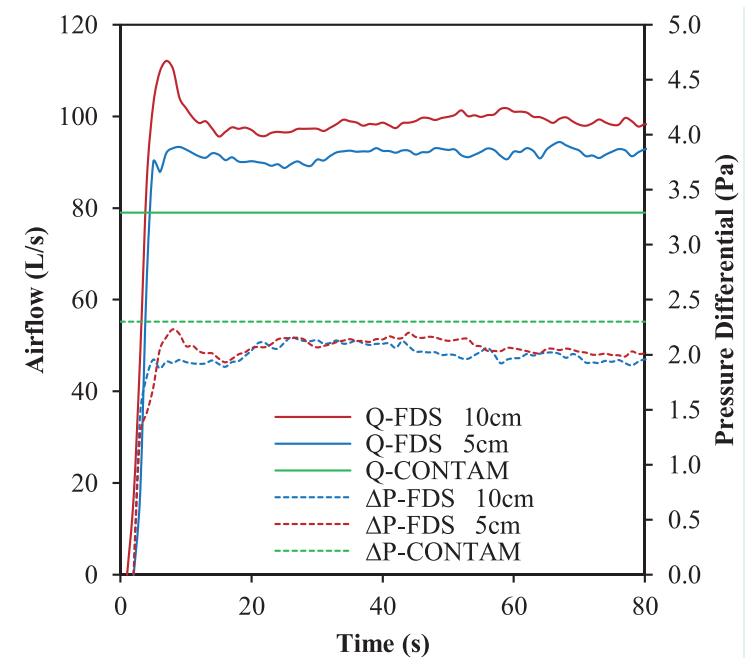

Fig. 8 Pressure differential at envelope and airflow at predictions at $1^{\text {st }}$ floor in FDS and CONTAM for Sim-X1

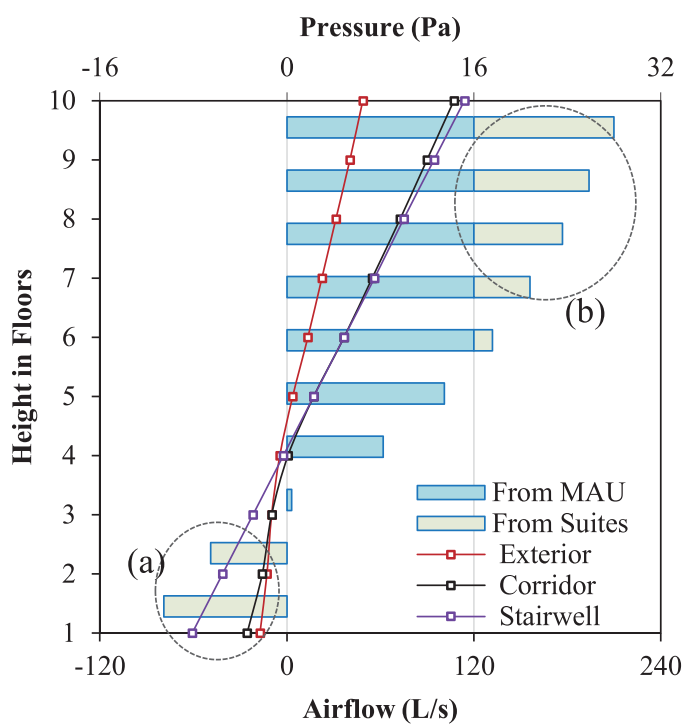

Fig. 9 Total ventilation delivered to suites in Sim-X1 "Leaky envelope and leaky corridor", where (a) indicates airflow from suite to corridor, (b) air originating from lower floors

shaft. For a leaky building in Sim-X1, the NPP occurs near the fourth floor. Below the NPP, air from suites and corridors enters the vertical. For the tighter building in Sim-X2, the NPP is below the ground floor, ensuring that contaminated air does not infiltrate the corridors.

Sim-X3 and Sim-X4 evaluated the effect of a combination of tight and leaky parameters for the corridor and envelope (Figure 11 and Figure 12). Increasing either the corridor or envelope tightness improves ventilation performance relative to Sim-X1. Airflow to the suites remained positive, ensuring that the migration of contaminants does not infiltrate the building. However, it can be noted that increasing the airtightness of corridors has the advantage of increasing the pressure relative to the suites. A higher relative pressure

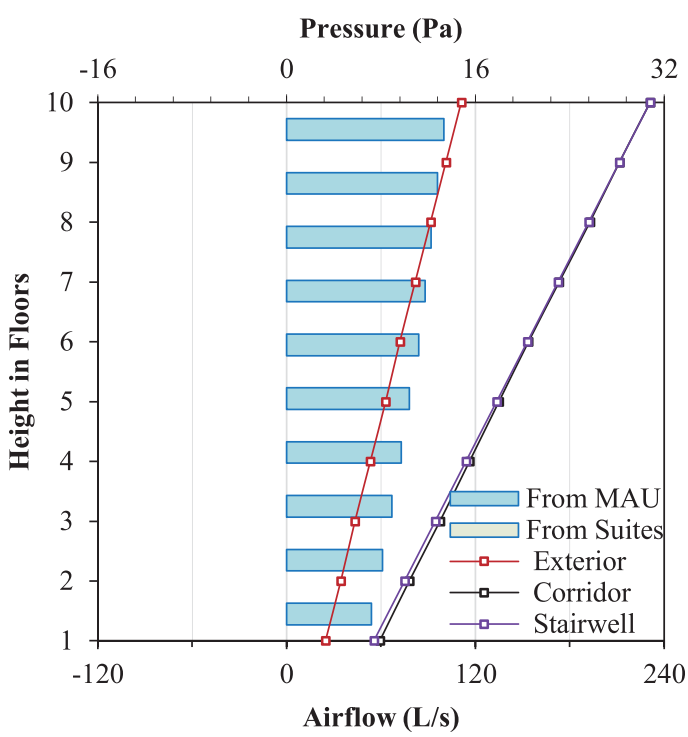

Fig. 10 Total ventilation delivered to suites in Sim-X2 "Tight envelope and tight corridor"

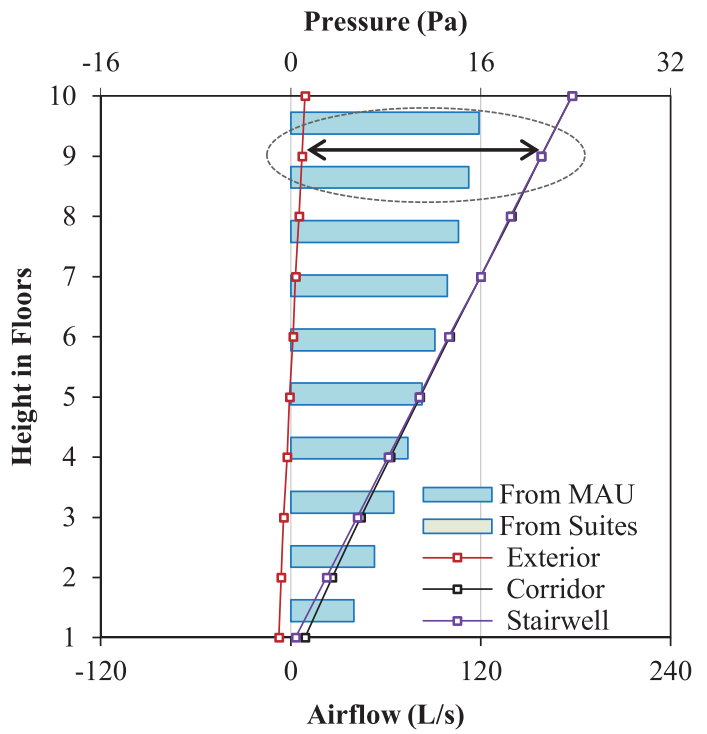

Fig. 11 Pressure and ventilation to suites in Sim-X3 "Leaky envelope and tight corridor" showing corridors are well pressurized relative to the suites

provides a higher margin of safety as dynamic forces such as wind, doors, and operable windows may affect the pressure differentials.

Sim-X5 demonstrates that increasing the vertical shafts' tightness can reduce the infiltration of air and increase the pressure of the corridor (Figure 13). Despite this, the pressure of the $1^{\text {st }}$ floor is not sufficient to prevent the infiltration of air from suites. However, it reduced the amount of airflow entering the vertical shafts to $40 \mathrm{~L} / \mathrm{s}$ on the first floor. This reduced the airflow from the shaft to corridors on the upper floors. The increased airtightness of shafts can reduce the amount of contaminated air entering the vertical shafts. 


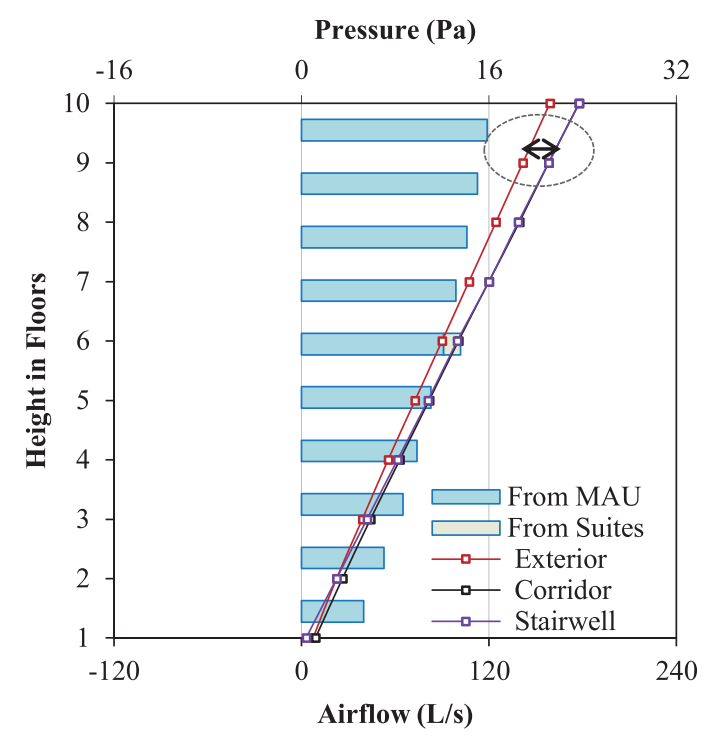

Fig. 12 Pressure and ventilation to suites in Sim-X4 "Tight envelope and leaky corridor" showing corridors are not well pressurized relative to suites

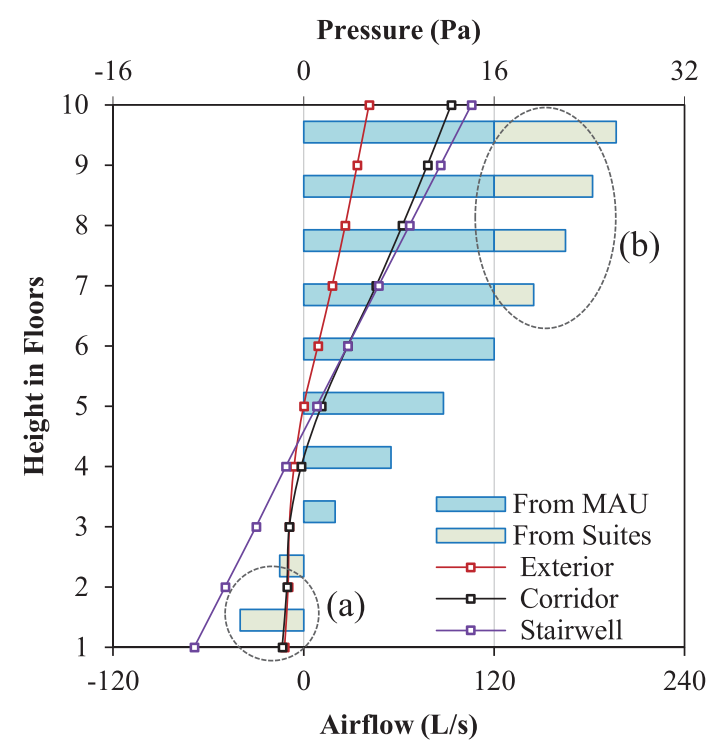

Fig. 13 Pressure distribution and ventilation delivered to suites in Sim-X5, when shaft leakage area is reduced (a) less airflow enter vertical shafts and (b) less airflow of contaminated air enter upper floors

In Sim-X6, the MAU supplied air is reduced to $20 \mathrm{~L} / \mathrm{s}$ on the $9^{\text {th }}$ floor (Figure 14). Insufficient supply causes a reduction in pressure relative to the vertical shaft. This results in significant airflow from the vertical shaft entering the corridor. As a result, simulations show that the airflow entering the corridor is predominantly from the vertical shafts. The vertical shafts may contain contaminated air, and the $9^{\text {th }}$-floor suites will receive the most exposure to this. The reduced air supplied by the MAU will have also reduce the dilution of contaminated air.

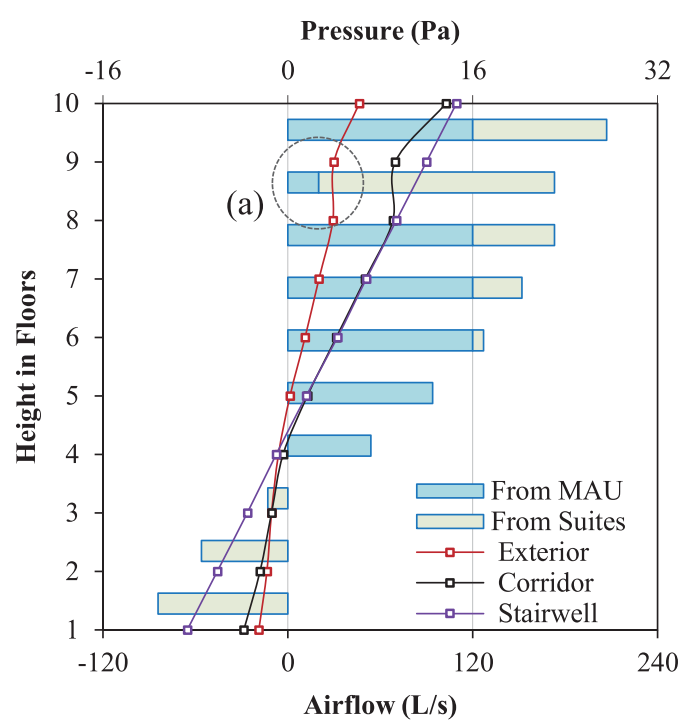

Fig. 14 Pressure distribution and ventilation delivered to suites in Sim-X6 with reduced MAU supply on the $9^{\text {th }}$ floor show that (a) airflow from shafts will increase where reduced supply occurs

\section{Exhaust ventilation}

The operation of exhaust fans can influence the airflow dynamic of the suite and the whole building. Suite exhaust reduces pressure within the suite compartment and will cause the infiltration of air from the corridor or envelope depending on the relative airtightness of each (Shaw 1993). Exhaust fans exist in most MURBs; however, the operation may vary between user-controlled, humidity-controlled, or constant operation.

Simulations evaluated the influence of exhaust fans on airflow in a MURB using parameters of leaky (Sim-X1) and tight (Sim-X2). Three exhaust ventilation schemes were used, which included no exhaust, exhaust of all suites, and exhaust suites of the first five floors. Suite exhaust fans removed $120 \mathrm{~L} / \mathrm{s}$ per floor. The ventilation per suite for each floor is illustrated for leaky envelopes in Figure 15 and tight envelopes in Figure 16.

In the leaky MURB, air enters the vertical shafts on the lower floors. The operation of exhaust fans reduced the airflow entering vertical shafts (Figure 15). In tight MURB simulations, exhaust fans' operation increased the ventilation received from the corridor (Figure 16). While exhaust fans improved the airflow on the lower floors, their operation may also increase the over-ventilation of upper floors. Operating suite exhaust fans on floors 1 to 5 improved the ventilation distribution amongst floors. This is observed in Figure 15 and Figure 16, where the suite exhaust increases the air entering the lower suites and decreases the over-ventilation of air to the upper suites. This suggests the use of higher exhaust rates on lower floors may improve the ventilation distribution amongst floors. 


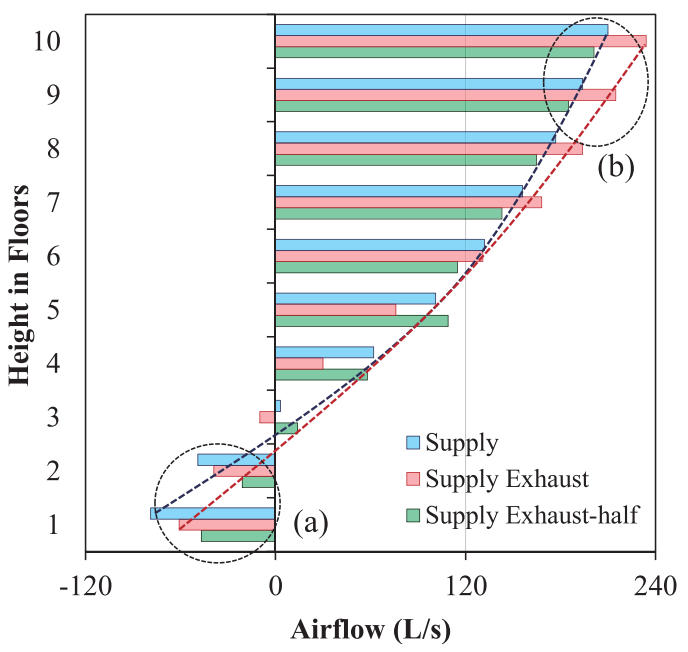

Fig. 15 Airflow delivered to suites in a leaky MURB (Sim-X1): (a) shows exhaust fans can reduce airflow leaving suites, (b) shows exhaust fans can increase over-ventilation of upper suites.

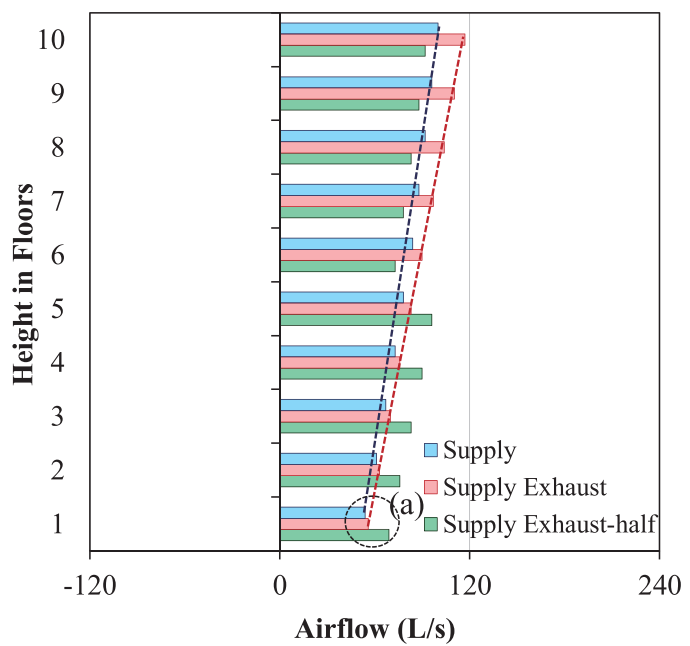

Fig. 16 Airflow delivered to suites in a tight MURB (Sim-X2): (a) shows that exhaust fans can increase ventilation of underventilated suites.

The effect of suite exhaust on air movement for a variation of airtightness parameters is illustrated in Figure 17. Additionally, the exhaust fan can affect the ventilation rate and dilute contaminants in the source of origin. The air change per hour $(\mathrm{ACH})$, demonstrates the ventilation rate relative to the suites volume. While the increase in infiltration from the exterior provides outdoor air, it may significantly reduce energy efficiency.

In a leaky MURB, Sim-X1, the exhaust fan reduced the amount of air infiltration the corridor. Assuming the air is well mixed, the infiltration of outside air would also dilute the contaminant concentration. In a tight MURB, Sim-X2, the exhaust fan did not significantly affect airflow between the corridor and suite. The exhaust operation resulted in the infiltration of exterior air.

\subsection{Contaminant spread}

The airtightness and ventilation parameters effect on airflow dynamics were visualized in FDS to illustrate contaminant concentrations throughout the building. A building section slice shows the concentration of contaminants for each simulation in Figure 18. A comparison with select CONTAM results is illustrated in Figure 19. Where CONTAM and FDS provided airflow agreement, a similar pattern of contaminants spread is expected to occur. This is demonstrated in Figure 19, which shows contaminants entering the same upper floors for select simulations. Contaminant concentrations differ, particularly on upper floors with FDS predicting higher yields. The large variation in concentration can be a result of minor variation in airflow and dilution from MAU supply.

The NPP location may change depending on leakage distribution and mechanical ventilation. For contaminant spread, it is worth noting the location where the pressure is equal between the vertical shaft and corridors, as well as the suites and corridor. The NPP of the vertical shaft and corridor (NPP-v) and the NPP of the suite's exterior (NPP-e) for each simulation are identified along with arrows indicating airflow direction.

Desirable airflow occurs when the corridor is pressurized relative to suites and vertical shaft. Airflow travels from the corridor into the suites or vertical shafts (escaping through the top vent). This is characterized by the NPP-e, between the corridor and suites, located beneath the first floor. The NPP-v, between the vertical shaft and corridor, is raised to the top. This indicates that no airflow enters corridors from suites or vertical shafts.

Undesirable airflow occurs when the corridor is at a negative pressurize relative to suites and vertical shaft. Airflow from the suites will enter the corridor will. This is characterized by the location of the NPP-e of the suites and corridor. Beneath this NPP-e, the migration of contaminants from suites to the corridor will occur. Thus, below the NPP-e, contaminated air may enter vertical shafts.

The airflow from the vertical shaft to corridors can spread contaminants if undesirable airflow exists. If the vertical shaft pressure exceeds the corridor's, airflow from the vertical shaft to the corridor will occur. This is characterized by the location of the NPP-v between the vertical shaft and corridor. Beneath the NPP-v, air will flow from the corridor to vertical shaft.

\section{Airtightness (Sim-X1 and Sim-X2)}

Airtightness affects the ability for a space to be pressurized relative to the exterior. Simulations illustrate that when the MAU supplied each floor with $120 \mathrm{~L} / \mathrm{s}$, the tight building parameters maintained positive pressurization of the 


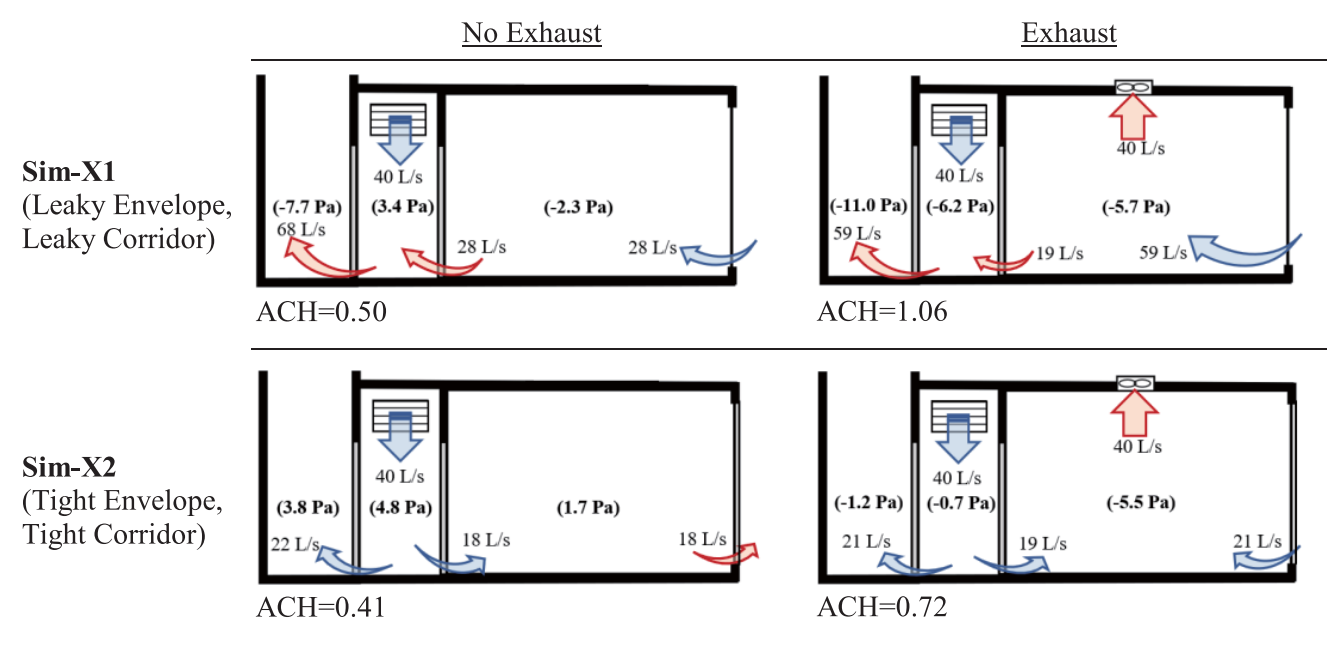

Fig. 17 Ground floor pressure and airflow per suite, with and without exhaust fans

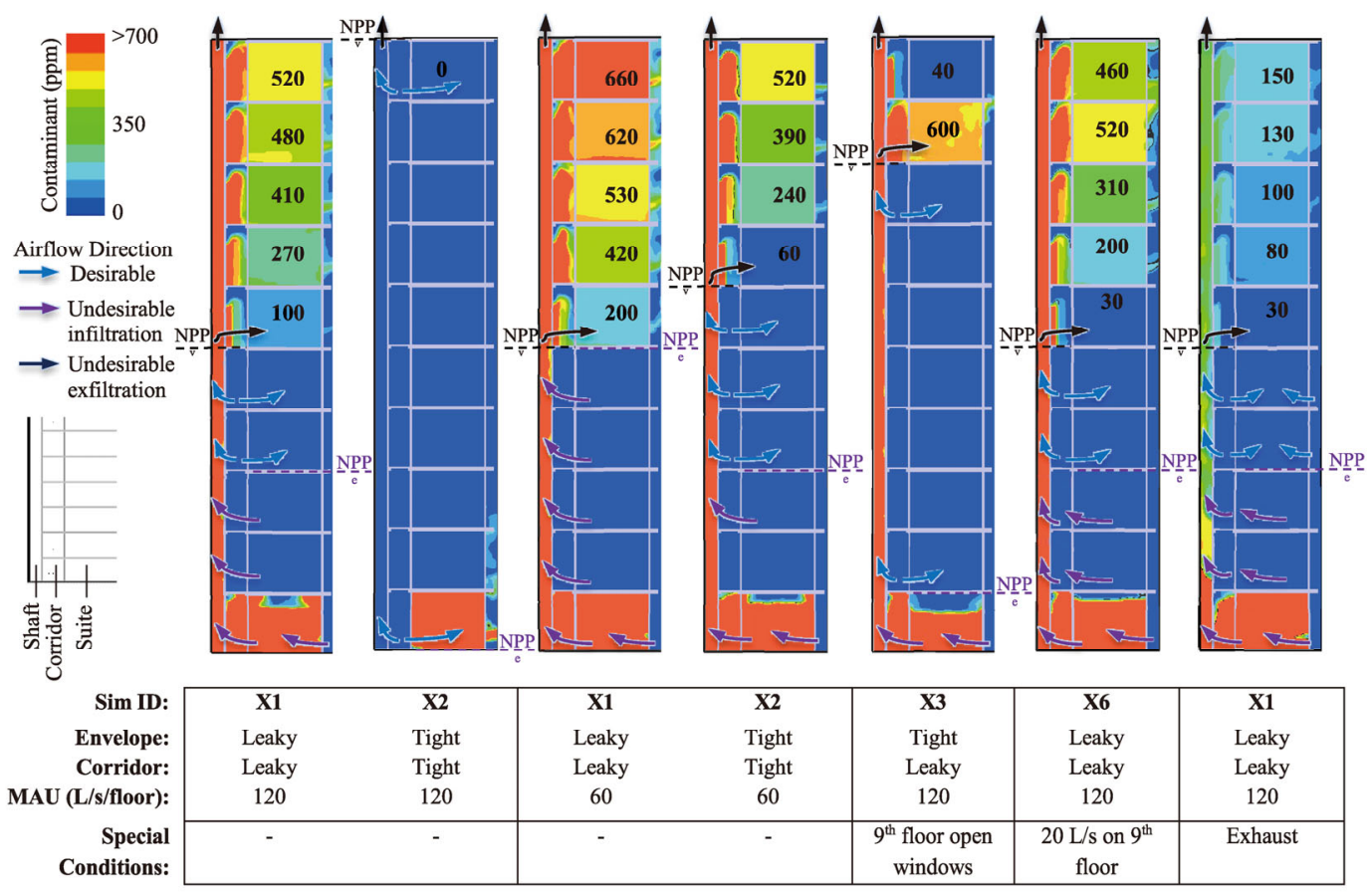

Fig. 18 Concentration of contaminants exhaled from the $1^{\text {st }}$-floor suite for variations in envelope tightness, supply ventilation, and openings.

corridors relative to the suites. This prevents the migration of contaminants from the suites to the corridor. As a result, the NPP of the corridors is beneath the first floor, indicating that air flows from the corridor to suites at all elevations. Airflow from corridor to vertical shaft does occur, however, the airflow will be from the MAU and not from suites.

The leaky building parameters resulted in negative pressures in the corridor with an NPP at mid-height. This allows the migration of air from suites into the shaft. As a result, floors above the NPP received air from the contaminated suites. The contaminant concentration is highest on upper floors as stack pressure differential increases with elevation. The supply of air to the corridor mixes and dilutes the contaminants.

\section{Supply air (Sim-X1 and Sim-X2)}

Reducing the supply air to provide $60 \mathrm{~L} / \mathrm{s}$ per floor allows the flow of contaminants from the ground floor suite into the vertical shafts for both tight and leaky parameters. Reducing the MAU supply also results in less dilution of contaminants. As a result, higher concentrations on the floors above the NPP-v are seen. The tight building parameters reduce the infiltration at the ground floor, resulting in fewer contaminants entering the vertical shaft. 


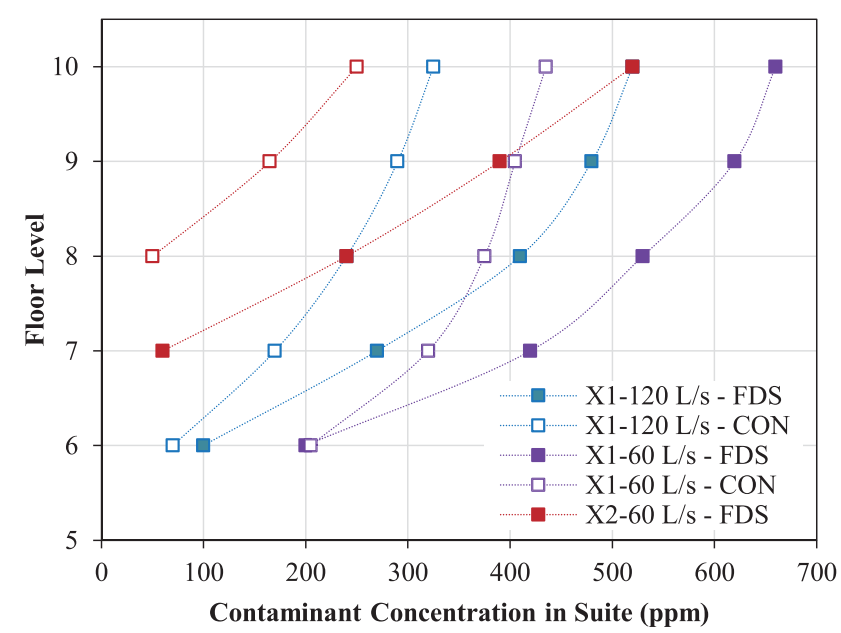

Fig. 19 Comparison of contaminant concentration in suites for select simulations in FDS and CONTAM

\section{Presence of open windows (Sim-X3)}

Efforts to increase airtightness can increase the pressure relative to the exterior. However, the presence of open windows provides a significantly large leakage area. Open windows may decrease the resistance to airflow entering from the vertical shafts, allowing contaminated air to enter, as illustrated in Figure 18.

\section{MAU supply balance (Sim-X6)}

The insufficient supply of air to a particular floor can reduce the corridor's pressure relative to the vertical shaft. For floors above the NPP, the flow of air from the vertical shaft may occur. Sim-X6 demonstrates that when the $9^{\text {th }}$ floor MAU supply is reduced to $20 \mathrm{~L} / \mathrm{s}$, large quantities of contaminated air enter the corridor from the vertical shafts. Additionally, the reduced supply of fresh air reduces the dilution, and suites receive a higher concentration of contaminated air.

\section{Exhaust ventilation (Sim-X1)}

When corridor pressurization is overcome by stack effect, the infiltration of air can spread contaminants from the $1^{\text {st }}$ floor throughout the building. Exhaust ventilation can reduce the concentration of contaminated suite air entering the corridor and vertical shaft. The simulations demonstrate that stack effect can be significant in leaky buildings, causing depressurization of the corridor and vertical shafts on lower floors. When this occurs, the migration of contaminants from suites on lower floors may enter vertical shafts. Suites above the NPP-v will be recipients of contaminated air originating from suites below the NPP-e.

\section{Discussion}

Simulations have demonstrated that stack effect may exacerbate two distinct problems, reduced ventilation of suites on lower floors and undesirable airflow (Figure 20). The decrease in corridor pressure on lower floors can cause reduced ventilation to enter suites. Further reduction in the corridor pressure may cause a reversal of airflow. When this happens, contaminants can spread to the upper floors of the building.

Sufficient pressurization of corridors relative to suites is necessary to prevent undesirable airflow. This can be accomplished by increasing building airtightness and providing corridors with enough supply air. While a corridor may have sufficient pressurization in mild weather, seasonal changes in ambient temperature may increase stack effect. Figure 21 illustrates how increasing airtightness may prevent

\section{(+) Possitive Pressure ( - ) Negative Pressure}
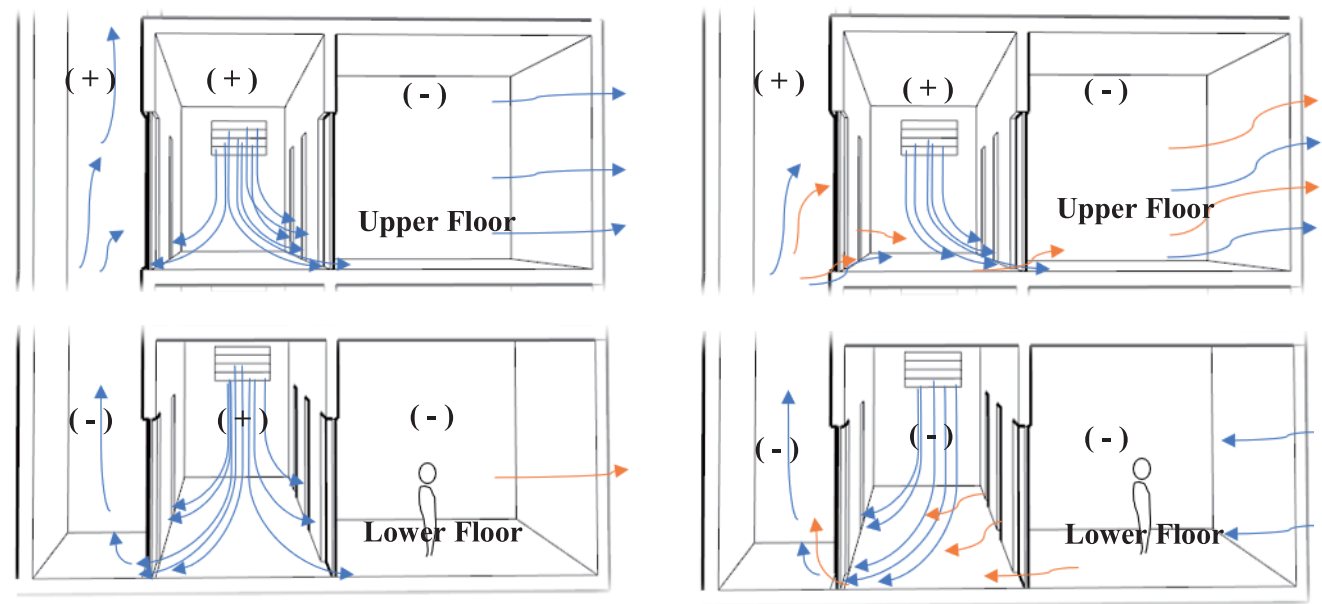

Reduced ventilation
Undesirable airflow

Fig. 20 Stack effect can cause reduced ventilation (left) and undesirable airflow (right) 


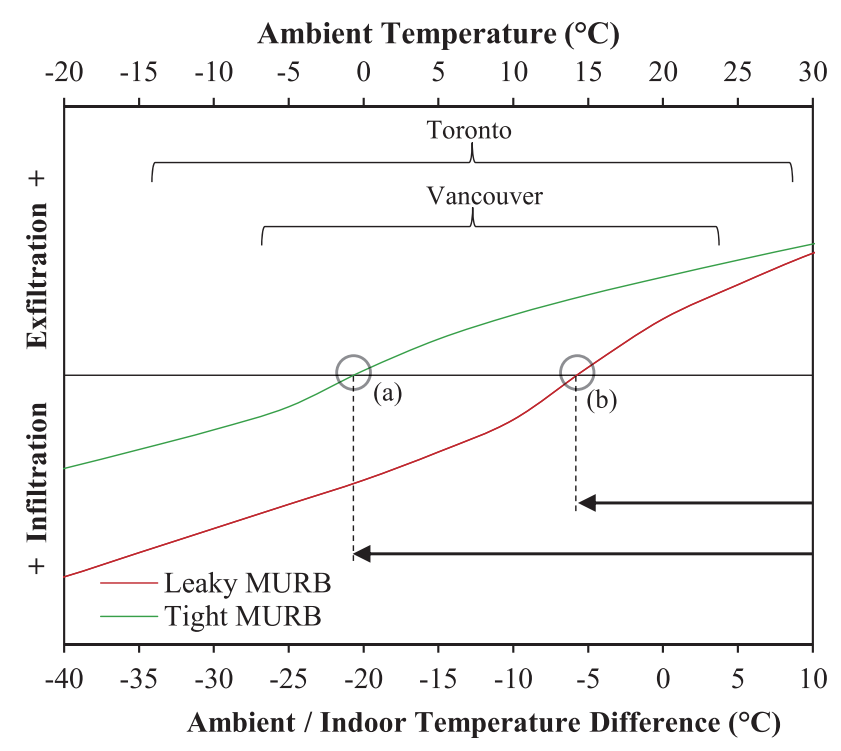

Fig. 21 With corridor pressurization, infiltration of corridors will be prevented for a greater range of ambient temperatures for Tight MURBs (a) versus Leaky MURBS (b)

infiltration for a greater range of ambient temperatures. For MURBs located in extremely cold climates, the magnitude and duration of undesirable airflow will be increased. For context, Figure 21 identifies the annual range of dry-bulb temperatures of Toronto and Vancouver. Colder climates are more susceptible to stack driven flow, and the coldest temperatures will often occur during the night, which coincides with when MURBs are most occupied.

\subsection{Improvements of existing buildings}

The optimal solution in addressing ventilation and contaminant spread in MURBs is to compartmentalize suites and provide direct ventilation (CMHC 2003; Lstiburek 2005; Ricketts 2014). While this is undoubtedly the best for performance, the cost of installing ducting or mechanical systems is very high. Due to this, many existing buildings remain uncompartmentalized. However, several improvements to the airtightness and mechanical systems may be capable of increasing the performance.

\subsubsection{Airtightness}

Increasing the airtightness of shafts, corridors, and envelopes can allow for increased corridor pressurization. To address air leakage of MURBs, the Canada Mortgage and Housing Corporation (CMHC) developed several detailed procedures for identifying and reducing leakage (CMHC 2017).

From the perspective of improving the pressurized corridor performance, it can be argued that the tightening of the core should be prioritized. Reducing leakage into the vertical shafts will increase the pressure of the corridor and deliver more airflow to suites (Figure 13). To avoid compromising pressure regimes, it is recommended that airtightness improvements occur from the core outward. In other words, improving the tightness of vertical shafts, corridors, and then envelope. A few strategies in improving airtightness in MURBs in cold climate include:

- Increasing the airtightness of the vertical shafts by reducing leakage at shaft doors. Stairwell doors can often be improved by the use of gaskets, weather-stripping, and door thresholds. However, elevator doors may provide a majority of the leakage and are difficult and costly to address, and may cause problems with door operation (Bukowski 2005).

- Increasing the airtightness of the corridor by addressing door undercuts. Suite door undercuts often vary in size. Where considerable variation exists, the use of weatherstripping or door replacement may be most practical. This may improve the pressurization and ventilation distribution of suites on a particular floor.

- Increasing the airtightness of the envelope. Envelope retrofits often occur for various reasons, and the airtightness may be improved when undertaken. The increase in airtightness can reduce infiltration due to stack effect. However, the corridor pressure relative to the suites may be reduced, increasing the likelihood of contaminant spread amongst suites on a particular floor. Operable windows can create large leakage areas, which can reduce the effectiveness of a tighter envelope. Studies have shown that even in extremely cold weather conditions, many occupants will have windows open (Ricketts and Finch 2013).

\subsubsection{Mechanical}

Studies of MURBs indicated that the air supplied by the MAU could vary significantly between floors. In one example, unintentionally closed fire dampers prevented the delivery of supply air (Ricketts 2014). This shows that MURBs are susceptible to operational inefficiencies that may remain unabated. Proper balancing may improve the ventilation to suites and maintain corridor pressurization. The air supplied to each floor would ideally be the amount required for ventilation to each suite. However, the influence of stack effect may change the ventilation received by upper and lower floors. A few strategies to improve corridor ventilation in a cold climate are:

- Ensure that MAU supply-air pressurizes the corridor relative to suites during the coldest periods of the year. This should focus on the lower floors, which are most susceptible to infiltration. Improvements may be achieved by balancing supply air amongst floors, as many buildings are rarely balanced (Ricketts 2014). In one MURB study, 
the total air delivered to corridors was only $40 \%$ of the measured MAU intake.

- Supply of air to corridors using barometric dampers could ensure that the amount of air reaching floors produces the optimal pressurization at all times. Implementing advanced control and automation over the supply air provided to corridors is discouraged by some experts due to complexity (Ricketts 2014).

- Exhaust fan operation can influence the airflow distribution. Simulations suggested that increasing the exhaust capacity on lower floors can improve the distribution of ventilation under stack effect.

- Exhaust fan operation of occupied suites can help dilute contaminated air at the source. If airflow from the suite to corridor occurs, the suite exhaust fans will have lowered the contaminant concentration.

\section{Conclusion}

For buildings in Canada, the pressurized corridor system's effectiveness may be severely compromised by stack effect during winter months. A decline in ambient temperatures can cause the corridor pressure and ventilation to be reduced for lower suites. A further decline in ambient temperatures can cause the corridors to become negatively pressurized relative to suites. When this occurs, air from lower suites will pass into corridors, allowing the spread of contaminants and potentially airborne disease. Measurements of many MURBs have confirmed that negative pressure relative to suites can occur during cold ambient temperatures (CMHC 2003; Ricketts et al. 2014).

The performance of many MURBs may be improved by addressing the building airtightness and ventilation systems. Increasing the building airtightness reduces the infiltration rate that occurs on lower floors. Increasing the airtightness of vertical shafts and corridors will allow for increased corridor pressure relative to the suite. A tighter building will require less MAU supply air to pressurize and ventilate suites. Addressing the airtightness and corridor ventilation in tandem may provide the optimal solution.

\section{Acknowledgements}

This work was supported by the Natural Sciences and Engineering Research Council of Canada [NSERC DG 2016-04176].

\section{References}

ASHRAE (1999). ASHRAE Standard 62-1999. Ventilation for Acceptable Indoor Air Quality. Atlanta, GA, USA: American Society of Heating, Refrigerating and Air-Conditioning Engineers.
ASHRAE (2009). Indoor Air Quality Guide. Best Practices for Design, Construction, and Commissioning. Atlanta, GA, USA: American Society of Heating, Refrigerating and Air-Conditioning Engineers.

ASHRAE (2017). Driving mechanisms for ventilation and infiltration. In: ASHRAE Handbook-Fundamentals (SI Edition). Atlanta, GA, USA: American Society of Heating, Refrigerating and AirConditioning Engineers.

Brasche S, Bischof W (2005). Daily time spent indoors in German homes-Baseline data for the assessment of indoor exposure of German occupants. International Journal of Hygiene and Environmental Health, 208: 247-253.

Bukowski RW (2005). Is there a need to enclose elevator lobbies in tall buildings? Building Safety Journal, 3(4), 26-31.

CMHC (2003). Ventilation Systems for Multi-Unit Residential Building: Performance Requirements and Alternative Approaches. Canada Mortgage and Housing Corporation.

CMHC (2005). Assessment of suite compartmentalization and depressurization in new high-rise residential buildings. Canada Mortgage and Housing Corporation. Research Highlight, Vol. 05, Iss. 112.

CMHC (2017). Air leakage control for multi-unit residential buildings. Canada Mortgage and Housing Corporation

De Paepe AE, Sierpowska J, García-Gorro C, et al. (2019). Ventilation and infiltration in high-rise apartment buildings. Journal of Chemical Information and Modeling, 53: 1689-1699.

Dols WS, Polidoro BJ (2015). CONTAM User Guide and Program Documentation. Version 3.2 (NIST Technical Note 1887).

Edwards C (1999). Modelling of Ventilation and Infiltration Energy Impacts in Mid and High-Rise Apartment Buildings. Report by Sheltair Scientific Ltd. For Canada Mortgage and Housing Corporation.

Finch G, Straube J, Genge C (2009). Air leakage within multi-unit residential buildings: Testing and implications for building performance. In: Proceedings of the 12th Canadian Conference on Building Science and Technology.

Francisco PW, Emmerich SJ, Schoen LJ, et al. (2020). ASHRAE Position Document on Airborne Infectious Diseases.

Gross D (1991). Estimating air leakage through doors for smoke control. Fire Safety Journal, 17: 171-177.

Gross D, Haberman W (1989). Analysis and prediction of air leakage through door assemblies. Fire Safety Science, 2: 169-178.

Jiang Y, Zhao B, Li X, et al. (2009). Investigating a safe ventilation rate for the prevention of indoor SARS transmission: an attempt based on a simulation approach. Building Simulation, 2: 281-289.

Kleinberg J, Neri R (2017). Spending Through the Roof: Tall Building Energy Wasted Through Passive Vents Building. Steven Winter Associates.

Klote JH, Milke JA (2002). Principles of Smoke Management. Atlanta, GA, USA: American Society of Heating, Refrigerating and AirConditioning Engineers.

Leslie Jones \& Associates (1991). HVAC Systems in Multi-unit High Rise Residential Buildings. Canada Mortgage and Housing Corporation.

Li Y, Duan S, Yu ITS, Wong TW (2005). Multi-zone modeling of probable SARS virus transmission by airflow between Flats in Block E, Amoy Gardens. Indoor Air, 15: 96-111. 
Li Y, Leung GM, Tang JW, et al. (2007). Role of ventilation in airborne transmission of infectious agents in the built environment? A multidisciplinary systematic review. Indoor Air, 17: 2-18.

Limb M (1998). Ventilation and Infiltration Characteristics of Lift Shafts and Stair Wells-A Selected Bibliography. Coventry, UK: Air Infiltration and Ventilation Centre.

Lstiburek JW (2005). Multifamily buildings: Controlling stack effectdriven airflows. ASHRAE Journal, 47(12): 38-48.

McGrattan KB, Hostikka S, McDermott R, et al. (2019). Fire dynamics simulator (FDS) validation technical reference guide volume 3: Validation. NIST Special Publication 1018.

Mølhave L, Krzyzanowski M (2003). The right to healthy indoor air: status by 2002. Indoor Air, 13: 50-53.

Persily A (2004). Building ventilation and pressurization as a security tool. ASHRAE Journal, 46(9): 18-26.

Persily A (2015). Challenges in developing ventilation and indoor air quality standards: The story of ASHRAE Standard 62. Building and Environment, 91: 61-69.

Ricketts L, Finch G (2013). Airflow in high-rise multi-unit residential buildings with respect to ventilation and IAQ. In: Proceedings of ASHRAE IAQ 2013.

Ricketts L (2014). A field study of airflow in a high-rise multi-unit residential building. Master Thesis, University of Waterloo, Canada.

Ricketts L, Finch G, Straube J (2014). Pressure difference and airtightness in tall building- theory and reality. In: Proceedings of the 4th NIBS Building Enclosure Science Technology Conference, Kansas City, MO, USA.

Shaw CY (1993). Application of tracer gas techniques to ventilation and indoor air quality investigations. Indoor and Built Environment, 2: 374-382.

Shaw CY, Tamura GT (1977). The calculation of air infiltration rates caused by wind and stack action for tall buildings. ASHRAE Transactions, 83(2): 145-158.

Strege S, Ferreira M (2017). Characterization of stack effect in high-rise buildings under winter conditions, including the impact of stairwell pressurization. Fire Technology, 53: 211-226.

Tamura GT, Shaw CY (1976). Studies on exterior wall air tightness and air infiltration of tall buildings. ASHRAE Transactions, 82(1): 122-134.

Tellier R, Li Y, Cowling BJ, et al. (2019). Recognition of aerosol transmission of infectious agents: A commentary. BMC Infectious Diseases, 19: 101.

van Doremalen N, Bushmaker T, Morris DH, et al. (2020). Aerosol and surface stability of SARS-CoV-2 as compared with SARS-CoV-1. The New England Journal of Medicine, 382: 1564-1567.

Wray CP, Theaker IG, Moffatt P (1998). Field testing to characterize suite ventilation in recently constructed mid- and high-rise introduction residential buildings. Report of Sheltair Scientific Ltd. to Canada Mortgage and Housing Corporation 